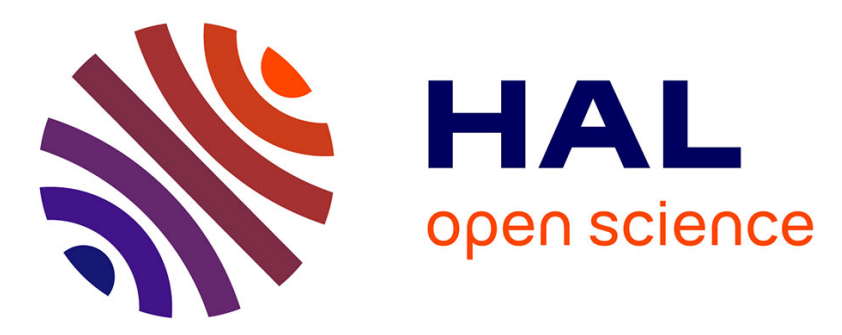

\title{
Sovereign Wealth Funds' cross-border investments: assessing the role of country-level drivers and spatial competition
}

\author{
Nicolas Debarsy, Jean-Yves Gnabo, Malik Kerkour
}

\section{To cite this version:}

Nicolas Debarsy, Jean-Yves Gnabo, Malik Kerkour. Sovereign Wealth Funds' cross-border investments: assessing the role of country-level drivers and spatial competition. Journal of International Money and Finance, 2017, 76, pp.68-87. 10.1016/j.jimonfin.2017.05.007 . hal-01251243v2

HAL Id: hal-01251243

https://hal.science/hal-01251243v2

Submitted on 7 Oct 2016 (v2), last revised 30 Nov 2020 (v3)

HAL is a multi-disciplinary open access archive for the deposit and dissemination of scientific research documents, whether they are published or not. The documents may come from teaching and research institutions in France or abroad, or from public or private research centers.
L'archive ouverte pluridisciplinaire HAL, est destinée au dépôt et à la diffusion de documents scientifiques de niveau recherche, publiés ou non, émanant des établissements d'enseignement et de recherche français ou étrangers, des laboratoires publics ou privés. 


\title{
Sovereign Wealth Funds' cross-border investments: assessing the role of country-level drivers and spatial competition ${ }^{\text {th }}$
}

\author{
Nicolas Debarsy ${ }^{\mathrm{a}, *}$, Jean-Yves Gnabo ${ }^{\mathrm{b}}$, Malik Kerkour ${ }^{\mathrm{a}, \mathrm{b}}$ \\ ${ }^{a}$ CNRS, LEO, UMR 7322, F-45067 Orléans \\ ${ }^{b}$ CeReFiM, University of Namur, Rempart de la Vierge 8, B-5000 Namur, Belgium.
}

\begin{abstract}
The aim of this paper is to identify the driving forces of cross-border investments emanating from Sovereign wealth funds and to test the existence of spatial competition among recipient countries. For this, we develop an original econometric framework that quantifies the role of spatial dependence in the location of investments, and that uses a modified version of the standard estimation procedure of spatial panel model, which accommodates the Inverse Hyperbolic Sine transformation of the dependent variable. This transformation copes with two critical features of net capital flows, namely an highly skewed distribution and the presence of zero and negative values. Using a largescale database, we provide evidence of negative spatial dependence, investments in one country being on average at the expense of its neighbors.
\end{abstract}

JEL classification: C18; C21; C23; G15; G32; G38; F21

Keywords: Sovereign Wealth Funds; Pull Factors; Spatial Econometrics; Inverse Hyperbolic Sine Transformation; Interactions.

\footnotetext{
${ }^{2}$ Nicolas Debarsy acknowledges financial support of the Region Centre Val de Loire (APR-IA 2014 00094514). JeanYves Gnabo acknowledges financial support of the ARC grant (Projet d'Actions de Recherche Concertées) \#13/17-055 granted by the Académie universitaire Louvain. We are grateful to Ingmar Prucha, Fei Jin, Hélène Raymond, Sophie Béreau, Oscar Bernal and the participants of the 15th workshop in spatial econometrics and statistics, the 8th Jean Paelinck Seminar, the $7^{\text {th }}$ French Econometrics Conference, the $26 \mathrm{EC}^{2}$ conference in Edimburgh and the participants of the Economics Seminar of the Department of Economics of University of Orléans.

${ }^{*}$ Corresponding author. Rue de Blois, BP 26739, Université d'Orléans, F-45067 Orléans, France. Tel: $+33(0) 2.38 .49 .24 .10$. Fax: $+33(0) 2.38 .41 .73 .80$

Email addresses: nicolas.debarsy@cnrs.fr (Nicolas Debarsy), jean-yves.gnabo@unamur.be (Jean-Yves Gnabo), malik.kerkour@unamur.be (Malik Kerkour)
} 
"I don't want European citizens to wake up in several months' time and find that European companies belong to non-European capital, which bought at the share price's lowest point"

"This might be an opportunity to create our own sovereign wealth funds"

(October 21, 2008, N. Sarkozy (President of France) at the European Parliament)

\section{Introduction}

Increasing financial integration as materialized by the sustain rise in both cross-border capital inflows and outflows has critically affected both advanced and emerging economies over the past decades, leading the academic community to examine various facets of this component of globalization such as the impact of financial integration on economic growth or on financial stability to cite a few. One remarkable feature of the recent years regarding international cross-border capital flows has been the emergence of a novel actor, namely Sovereign wealth funds (SWFs) which has rapidly become a major force in financial markets worldwide. SWFs are public investment agencies located for their vast majority in developing economies ${ }^{1}$ which manage part of the assets owned by national governments resulting from excess of exchange foreign reserves, oil or gas receipts as well as trade surpluses. Whether or not capital flows emanating from these state-owned entities are in the interest of the target country has been the object of heated debates within political circles and the general public. As illustrated in the above quote from the former French President, Nicolas Sarkozy, there have been long lasting fears and reluctance regarding the arrival of SWFs in local markets mainly due to their lack of transparency as well as to the belief that those investments were designed to exert political influence on target firms or countries and to access foreign technology. Today, however, SWFs constitute a major source of capital for world economies with assets under management amounting to $\$ 7.243$ trillion, leading most governments as noted by Megginson and Fotak (2014) to "court" SWF investments.

Given their increasing importance in advanced and emerging economies, the question of how countries can attract capital flows emanating from SWFs has become of major importance. In this paper, we propose to identify both country-level determinants and spatial interaction effects of cross-border SWF net flows. In particular, we examine the existence of spatial competition among recipient countries of SWF investments that is whether increased capitals received by one target

\footnotetext{
${ }^{1}$ Among the 79 SWFs listed in the SWF institute website in 2016 only 21 percent are located in developed economies according to the taxonomy adopted by the United Nations; the rest of SWFs are located in developing economies (67 percent) or transition economies (12 percent).
} 
country is on average at the expense of its neighbors. Documenting empirically the drivers of net capital flows is not easy. Neither is the assessment of spatial effects, as it requires addressing a set of important econometric issues. As we argue later in the paper, a careful treatment of these issues is however critical to obtain reliable results. For these reasons, we develop in this analysis an original econometric framework that allows (i) to explicitly model and to test the existence of spatial dependence in investment location and (ii) to accommodate a well-known feature of cross-border capitals: the presence of skewed distributions of net investment flows due to extreme values as well as zero and negative net flows. Our procedure is then applied to an original large-scale database containing SWF's net flows to 43 countries including both advanced and emerging economies over the 2004-2009 period.

Along with the surge in SWF'' cross-border investments, there has been an increasing interest in the literature in the determinants of SWFs' investments either at the firm level or at the country level. In the former case, the literature builds on existing evidence in corporate finance which has shown that firm-level conditions, such as firm-size (market capitalization, sales), firm-specific risk indicators (leverage, cash of firm, degree of financial constraint, analyst coverage, turnover) as well as firm-performance (ROA, ROE, CAPEX, stock market return, dividend yield) are the main drivers of firm attractiveness for capitals (Kotter and Lel, 2011; Fernandes, 2011; Avendano, 2010). With respect to these three criteria, Kotter and Lel (2011), Karolyi and Liao (2010) and Avendano (2010) argue that SWFs tend to invest in large and poorly performing companies which are financially and cash constrained. Beyond firm characteristics, macroeconomic factors along with the financial and institutional factors of the target country have also been documented as important in the decision process of SWF (see Chhaochharia and Laeven (2008) and Karolyi and Liao (2010) among others). Hence, Knill et al. (2012) find that the decision to invest depends positively on the correlation between the market return on the SWF and that on the target country's national market index, mitigating the role of risk diversification in the decision of investment. In the same vein, Fotak et al. (2008) find that SWFs investments tend to be concentrated, especially in the financial sector. Separating the decision to invest from the amount invested, Knill et al. (2012) conclude that the economic and financial variables are important factors for explaining the former but matter less in determining the size of investment.

One important dimension of SWFs decision which is absent from the above discussion pertains to the international allocation of capital. Is there evidence of domestic or foreign equity bias? Do cross-border investments concentrate in specific regions? And if so, why? These are examples of 
questions related to the spatial dimension of the portfolio allocation which have been discussed in the literature on SWF without being fully addressed (Megginson et al., 2013). In what follows, we review key elements of those discussions along with selected arguments regarding the specific role of interactions in explaining capital investments flow among countries.

The primary remarkable feature regarding the spatial allocation of SWFs' capitals lies in the large share of foreign assets hold in their portfolio. Looking at investments made by 15 SWFs over the period 1985-2011, Bortolotti et al. (2013) and Megginson et al. (2013) report that nearly 70\% are channeled outside the home country. These figures starkly contrast with those usually reported for other categories of funds such as mutual funds or pension funds which exhibit very strong home equity bias (Bortolotti et al., 2013; Megginson and Fotak, 2014). At least two explanations help understand this feature. First, conversely to other types of funds, one of the primary missions of SWF is to help its home country stabilize its wealth. Accordingly, cross-border investments are used as a diversification device which mitigates the impact of domestic economic downturns on the national wealth. Second, large demand in domestic assets could end up building financial bubbles in local markets. This risk is particularly important for countries hosting SWFs as their economies are often of small size compared to the amount under management.

Another interesting feature related to the spatial dimension of cross-border capitals pertains to the concentration of SWF investments in specific regions, notably in western economies which benefit from the lion's share of international SWF capitals with more than $50 \%$ of them (see Megginson and Fotak (2014) and the Sovereign wealth fund institute). The rest is mainly invested in emerging market economies with specific regions such as Asia-Pacific receiving large flows and others such as Latin America being nearly absent from the map. Traditional arguments from the literature on international asset allocation to explain this feature relate to restrictions on international capital flows, institutional barriers or transaction costs. For instance, high transaction costs prevent from widespread investments of capital across countries and in turn from optimal diversification of risk. Regional concentration can also stem from the existence of privileged relationship between the home and the target country. For instance, Knill et al. (2012) and Chhaochharia and Laeven (2008) show that SWF tend to invest in countries with prevailing trade links. This feature is consistent with former results from the literature on foreign direct investment and international asset allocation which emphasize the critical role of symmetric information (cost) and familiarity in explaining the spatial allocation of international investments (Beugelsdijk and Frijns, 2010). Likewise, Hau (2001) shows that investors overweight assets they know better in their portfolio such as those issued 
by firm located in a country they are more familiar with or by multinationals. Those arguments have been more recently discussed within the frame of the behavioral finance theory in which investors are assumed to be boundedly rational. Accordingly, they consider foreign markets as more risky than they truly are, if they are located far away (Solnik, 2008), concentrating their investments in regions in which they have either information advantage or perceived familiarity. In a related context, Portes and Rey (2005) highlight the strong impact of the distance on crossborder equity flows. To explain this result, they argue that informational asymmetries lead to higher transaction costs between distant economies. ${ }^{2}$ Aviat and Coeurdacier (2007) point out that the very large impact of distance on asset holdings in Portes and Rey (2005) is the consequence of the complementarity between trade in goods and trade in assets. As such, they show that geographical distance, understood as transportation costs, affects asset holdings mainly through its impact on trade in goods. So far, various proxies have been proposed in the literature to measure the level of familiarity between investors and target firms or economies such as language, trade, culture and geographic distance .

Spatial dependence in capital flows can also simply stem from well-documented economic and financial interactions across world economies. As such, countries receiving capitals from SWFs are open economies which trade with other partner countries or investing themselves in other countries. Those economic and financial relationships create physical dependence across countries that can make capital flows from SWFs in a given country to be complementary and then to depend on what its neighbors receive. Such a complementarity in investments made in different countries has been documented for instance in the literature on foreign direct investments (FDI) that specifically concentrates on conditions of multinational enterprise (MNE) choice of location for their production plan.

The above discussion suggests the existence of spatial dependence in aggregate flow of investments received by host countries. Whether this dependence is playing a significant role in practice is still unknown. Neither is the actual sign of the spatial correlation as two opposite effects can be at play. Hence, if the choice to invest in a country is primarily based upon information or familiarity criteria, we do expect a positive sign: countries sharing similar characteristics should attract SWFs' capital more or less to the same extend. To illustrate this relationship, consider a SWF deciding to incur search and informational costs for investing in a specific country. By doing

\footnotetext{
${ }^{2}$ Separating out cultural proximities from pure informational symmetries remains a challenge for the empirical literature (Portes and Rey, 2005).
} 
so, the fund implicitly becomes more informed about countries having a similar profile to the target country, thereby being also more likely to invest in these countries. Increased investments in one country should therefore be positively correlated with investments in its neighborhood (viewed as countries sharing similarities). Still, the sign of the relationship holds as long as countries are not set in competition. If similar economies are set in competition the sign is reversed and the expected spatial correlation should be negative due to a continuous reallocation or re-balancing mechanism over time: an increase in the investment done in one country at time $t$ comes at the expense of a similar country.

Although the literature on SWF determinants has been important over the past decade (Knill et al., 2012; Megginson et al., 2013), empirical studies have been silent on one critical aspect of cross-border investments: the specific role of spatial interactions between host countries to explain the capitals' allocation. The present paper aims to fill the gap by assessing the effect of domestic determinants and spatial interactions on sovereign funds capitals' net flows. To this end, we adopt the perspective of the host country. As such, we can identify the factors leading an economy to attract more or less capitals emanating from SWFs while being agnostic upon their origin. This approach is in line with a large strand of the literature on foreign direct investment ( $\mathrm{Yu}$ and Walsh, 2010; Kristjánsdóttir, 2005; Bénassy-Quéré et al., 2007) but departs from the traditional bilateral approach often adopted in the SWF literature (Knill et al., 2012; Megginson et al., 2013). Hence, our contribution to the existing literature is twofold. First, our approach is designed to explicitly take into account interactions in SWF's investment flows. As discussed above, there are ample anecdotal and more formal evidence from both the academic literature and professional commentators that SWF investments concentrate on specific geographic zones. ${ }^{3}$ Accordingly, we conjecture that the amount flowing in and out a country is not independent from the amount of capital attracted by neighboring countries, the neighborhood being alternatively defined by geographic, cultural or economic proximity in this paper. To formally test the existence of spatial interactions in SWFs investment net flows, we propose to rely on the recent developments of spatial panel data models (Lee and Yu, 2010a,b, 2012). To the best of our knowledge, this approach has never been used to analyze SWFs' cross-border investments. The second contribution lies in the treatment proposed to deal with the so-called problem of skewness in the distribution of capital flows (Zhang, 2014, p.136). More specifically, the amount invested every year in target

\footnotetext{
${ }^{3}$ see www.swfinstitute.org/sovereignwealthmap.html
} 
countries exhibits extreme values but also null and negative values. To deal with the problem of extreme values which can severely bias estimated parameters, the literature usually proposes to apply a log-transformation (Bénassy-Quéré et al., 2007). This step has the advantage to dampen the dispersion in the data, and especially the outliers, but cannot deal with zero and negative values. In this paper, we propose an original procedure to deal with this problem by using the Inverse Hyperbolic Sine transformation of the dependent variable, developed by Johnson (1949) and applied to econometrics by Burbidge et al. (1988), which allows, in addition to reduce the skewness of the distribution and the impact of outliers, to take care of possible zeros and negative values in the dependent variable. To the best of our knowledge, this transformation has never been applied to spatial econometrics models. We contribute therefore to the literature by developing the estimation procedure accordingly. Specifically, we derive the likelihood function that accommodates the transformation and compute the associated matrices of impacts of a change of a regressor on the dependent variable. Given the feature in the data it can deals with, there are obliviously many research in macroeconomics and finance such as modeling of foreign direct investment and trade that could benefit from this transformation and the associated estimation procedure we propose.

The reminder of the paper is as follows: In Section 2, we present the spatial autoregressive model with the IHS transformation. Section 3 provides some details regarding the data and Section 4 reports and discuss our empirical findings. Finally, Section 5 concludes.

\section{Econometric methodology}

In this contribution, the dependent variable is defined as the net flows of investments from sovereigns funds in a given country and is highly skewed to the right (see Figure 1 and information given in Section 3.1). To solve this problem of outliers which can severely bias the estimated parameters of the model, the traditional approach consists in log-transforming the variable so that the distribution of the transformed variable is closer to a normal distribution. However, in our case, the dependent variable also takes on null and negative values. Different solutions have been proposed in the literature to deal with the limits of standard log-transformation. Hence, in the presence of positive and null values of the dependent variable (presence of zero flows for instance), we can simply disregard the concerned observations. However, this approach may result in substantial loss of information (Aviat and Coeurdacier, 2007). An alternative solution consists in adding an arbitrary value (typically 1 ) to the concerned observations and include a dummy in the model for the modified values of the dependent variable (for further details, see Raballand, 
2003; Disdier and Head, 2008). However, the zero-flow dummy variable could be endogenous since it depends on the value taken by the dependent variable. Besides, Linders and De Groot (2006) critic the arbitrariness of the chosen value to replace zeros. Frankel et al. (1997) also indicates that this transformation biases the least squares estimator. Another solution to deal with zero flows would be to use a Tobit model (Eaton and Tamura, 1994). However, this approach might not be suited for our case since in addition to zero investments, we also face negative values of net flows. Hence, our dependent variable cannot be considered as left censored.

In this contribution, we rely on a different approach which consists in using an alternative transformation to the logarithm. We apply the Inverse Hyperbolic Sine (IHS) transformation to the dependent variable. This IHS transformation, developed by Johnson (1949) and applied to econometrics by Burbidge et al. (1988) has been used among others in the context of Engel curve by Reynolds and Shonkwiler (1991); Yen and Jones (1997), to assess the impact of tax incentives on savings by Pence (2006) and to studies aimed at explaining wealth (Kennickell and Sunden, 1997; Carroll et al., 2003; Kapteyn and Panis, 2003). One of the advantages of the IHS transformation is that it allows the dependent variable to take on both positive and null values but also accommodates negative values while still dampening the outliers and is known to better handle extreme values than the Box-Cox transformation (Burbidge et al., 1988). ${ }^{4}$ The IHS transformation applied to a variable $y$ is presented in equation (1).

$$
\omega(y)=\frac{\ln \left(\theta_{0} y+\left(\theta_{0}^{2} y^{2}+1\right)^{0.5}\right)}{\theta_{0}}=\sinh ^{-1}\left(\theta_{0} y\right) / \theta_{0}
$$

This transformation is defined for all values of the scaling parameter $\theta_{0}$. Besides, as it is symmetric around 0 , we consider only $\theta_{0} \geq 0$. Also, for large values of $y$, the IHS transformation corresponds to a vertical displacement of the logarithm: $\ln \left(\theta_{0} y+\left(\theta_{0}^{2} y^{2}+1\right)^{0.5}\right) \approx \ln 2 \theta_{0}+\ln y$. It can thus be interpreted in exactly the same way as a standard logarithmic dependent variable but unlike the logarithm, the IHS transformation is defined at zero and for negative values. As $\theta_{0}$ approaches 0 , the IHS transformation is linear for a larger proportion of its domain while it approximates the logarithmic transformation in a larger proportion of its domain when $\theta_{0}$ is larger (Pence, 2006). Finally, we note that $\partial \omega(y) / \partial y=\frac{1}{\sqrt{1+\theta_{0}^{2} y^{2}}}$.

\footnotetext{
${ }^{4}$ Bickel and Doksum (1981) extend the Box-Cox transformation so that it can also handle negative value, but this transformation remains undefined when the variable takes on zero values. Also, John and Draper (1980) propose the "modulus transformation", another extension of the Box-Cox transformation, to address negative and zero values. However, this modulus transformation is not scale invariant, to the contrary of the IHS transformation used here.
} 
In this paper, we estimate a spatial panel data model with random effects. Our procedure uses the approach developed by Mundlak (1978) and extended to spatial panel models by Debarsy (2012) to correct for the possible correlation between individual effects and regressors.

The random effects specification is presented in equation (2).

$$
\begin{aligned}
\omega(Y)_{n t} & =\lambda_{0} W_{n} \omega(Y)_{n t}+X_{n t} \beta_{0}+U_{n t} \quad t=1, \cdots, T \\
U_{n t} & =c_{n 0}+V_{n t}
\end{aligned}
$$

where $Y_{n t}$ is the vector of the dependent variable for the $n$ individuals at period $t$ and $X_{n t}$ is the matrix of exogenous regressors at period $t$ of dimension $n \times K$. The error term $U_{n t}$ is composed of 2 terms: $\mathbf{c}_{n 0}$, the vector of individual effects and $V_{n t}=\left(v_{1 t}, \cdots, v_{n t}\right)$, the vector of idiosyncratic errors. We further have that $W_{n}$ is a square matrix of dimension $n$ modeling interactions between observations. Its construction is discussed in Section 3. Finally, $\beta_{0}$ is the vector of dimension $k \times 1$ of unknown parameters to be estimated and $\lambda_{0}$ is the unknown coefficient measuring the intensity of interactions between observations, to be estimated.

Stacking model (2) for all periods, we obtain:

$$
\begin{aligned}
\omega(Y)_{n T} & =\lambda_{0}\left(I_{T} \otimes W_{n}\right) \omega(Y)_{n T}+X_{n T} \beta_{0}+U_{n T} \\
U_{n T} & =Z_{c} c_{n 0}+V_{n T}
\end{aligned}
$$

with $Z_{c}=\iota_{T} \otimes I_{n}$ and where $\iota_{T}$ is a unit column vector of dimension $T$. The variance-covariance matrix of $U_{n T}$ is

$$
\Omega_{n T}=\left(\iota_{T} \iota_{T}^{\prime} \otimes I_{n}\right) \sigma_{c}^{2}+\sigma^{2} I_{T} \otimes I_{n}
$$

Using the results of Wansbeek and Kapteyn (1982), we can rewrite the var-cov matrix in (4) as follows:

$$
\Omega_{n T}=\left(T \sigma_{\alpha}^{2}+\sigma^{2}\right)\left(\frac{1}{T} \iota_{T} \iota_{T}^{\prime} \otimes I_{n}\right)+\sigma^{2}\left(E_{T} \otimes I_{n}\right)
$$

where $E_{T}=I_{T}-\frac{1}{T} \iota_{T} \iota_{T}^{\prime}$ is the demeaning operator. We can finally write $\Omega_{n T}=\sigma^{2} \Sigma_{n T}$, with

$$
\Sigma_{n T}=\phi^{-1}\left(\frac{1}{T} \iota_{T} \iota_{T}^{\prime} \otimes I_{n}\right)+\left(E_{T} \otimes I_{n}\right)
$$

where $\phi=\frac{\sigma^{2}}{\left(T \sigma_{c}^{2}+\sigma^{2}\right)}$. By using Breusch (1987) results, we compute $\Sigma_{n T}^{-1}=\phi P_{W}+Q_{W}$ and $\left|\Sigma_{n T}\right|=\phi^{-n}$, with $P_{W}=\frac{1}{T} \iota_{T} \iota_{T}^{\prime} \otimes I_{n}$ and $Q_{W}=E_{T} \otimes I_{n}$.

Asymptotic properties of this model have been developed by Lee and Yu (2012) and the assumptions underlying these asymptotic properties for the QML estimator are reproduced below for the sake of clarity. 
Assumption 1. $W_{n}$ is a non-stochastic spatial weights matrix with zero diagonals

Assumption 2. The disturbances $\left\{v_{i t}\right\}, i=1, \cdots, n$ and $t=1, \cdots, T$ are i.i.d. across $i$ and $t$ and normally distributed with zero mean, variance $\sigma_{0}^{2}$ and $\mathcal{E}\left|v_{i t}\right|^{4+\eta}$ for some $\eta>0$.

Assumption 3. $S_{n}(\lambda)=I_{n}-\lambda W_{n}$ is invertible for all $\lambda \in \Lambda$, where $\Lambda$ is a compact interval. Furthermore, $\lambda_{0}$ is in the interior of $\Lambda$.

Assumption 4. The elements of $X_{n t}$ are non-stochastic and bounded, uniformly in $n$ and $t$. Also, under the asymptotic setting in assumption 6, the limit of $\frac{1}{n T} \sum_{t=1}^{T} X_{n t}^{\prime} X_{n t}$ exists and is nonsingular.

Assumption 5. $W_{n}$ is uniformly bounded in both row and column sums in absolute value (for short, UB). Also, $S_{n}(\lambda)^{-1}$ is $U B$, uniformly in $\lambda \in \Lambda$.

Assumption 6. $n$ is large, where $T$ can be finite or large.

Assumption 7. $\mathbf{c}_{n 0} \sim N\left(0, \sigma_{c}^{2} I_{n}\right)$ and $V_{n t}$ are i.i.d. and independent of $X_{n T}$. Also, $\mathbf{c}_{n 0}$ is independent of $V_{n T}$.

Assumption 1 is a normalization assumption which simply states that an observation does not interact with itself. Assumption 2 states the regularity conditions for the error term. It imposes homoskedasticity of the error term, a necessary condition for the QMLE to be consistent (see Lin and Lee, 2010). The invertibility condition in Assumption 3 guarantees the existence of equation (2). Besides, Assumption 3 imposes the parameter space $\Lambda$ to be a compact set.

Assumption 4 states that if explanatory variables are included in the model, they should be uniformly bounded. Finally, Assumption 5 guarantees that spatial autocorrelation is limited to a manageable degree (Lee and Yu, 2010a) while Assumption 7 is needed to avoid correlation between independent variables and the error term. Defining $\gamma=\left(\theta, \lambda, \beta^{\prime}, \phi, \sigma^{2}\right)^{\prime}$ and $\eta=\left(\theta, \lambda, \beta^{\prime}\right)^{\prime}$, the log-likelihood function associated to model (2) is written as:

$$
\begin{aligned}
\ln L(\gamma)=-\frac{n T}{2} \ln (2 \pi) & -\frac{n T}{2} \ln \left(\sigma^{2}\right)+\frac{n}{2} \ln \phi \\
& +T \ln \left|I_{n}-\lambda W_{n}\right|-\frac{1}{2} \sum_{i=1}^{n} \sum_{t=1}^{T}\left[\ln \left(\theta^{2} y_{i t}^{2}+1\right)\right]-\frac{1}{2 \sigma^{2}} U_{n T}^{\prime}(\eta) \Sigma_{n T}^{-1} U_{n T}(\eta)
\end{aligned}
$$

where $U_{n T}(\eta)=\omega(Y)-\lambda\left(I_{T} \otimes W\right) \omega(Y)-X \beta$.

Also, $T \ln \left|S_{n}(\lambda)\right|-\frac{1}{2} \sum_{i=1}^{n} \sum_{t=1}^{T} \ln \left(\theta^{2} y_{i t}^{2}+1\right)$ is the Jacobian of the transformation, composed of two terms. $T \ln \left|S_{n}(\lambda)\right|$ refers to the classical term coming from the SAR specification while $-\frac{1}{2} \sum_{i=1}^{n} \sum_{t=1}^{T} \ln \left(\theta^{2} y_{i t}^{2}+1\right)$ is the derivative of the transformed dependent variable with respect to the original dependent variable. 
According to Mundlak (1978), the random effects model is a misspecified version of the fixed effects model because it ignores the possible correlation between individual effects and regressors. By controlling for this correlation, he shows that the coefficients of the random effects specification are identical to those of the fixed effects model. He thus proposes to set an auxiliary regression that will capture this possible correlation. As individual effects are time invariant, they should be correlated with the permanent component of the regressors, namely their time-average.

Hence, Mundlak (1978) proposes to augment the random effects model with the time-mean of independent variable to control for the possible correlation between individual effects and regressors. Debarsy (2012) extends this approach to spatial panel data models. Adapting this approach to our model, we get:

$$
\begin{aligned}
\omega(Y)_{n t} & =\lambda_{0} W_{n} \omega(Y)_{n t}+X_{n t} \beta_{0}+\overline{\widetilde{X}}_{n} \pi_{0}+U_{n t} \quad t=1, \cdots, T \\
U_{n t} & =\alpha_{n 0}+V_{n t}
\end{aligned}
$$

where $\widetilde{X}$ is the matrix of independent variables without the constant term, $\widetilde{X}_{n}=\frac{1}{T} \sum_{t=1}^{T} \widetilde{X}_{n t}$ is the time average of $\widetilde{X}$ for all individuals and $\alpha_{n 0} \sim I N\left(0, \sigma_{\alpha}^{2}\right)$.

The presence of correlation between individual effects and independent variables can be assessed by testing whether the hypothesis $\pi=0$ can be rejected, using for instance a Wald or likelihood ratio test.

\subsection{Model interpretation}

Interpretation of the results in spatial model is not trivial. Model (2) is an implicit form model estimated by maximum likelihood. However, in order to compute the impact of a change of a regressor on the dependent variable, we need to rely on the reduced form of the model, which is shown in equation (8).

$$
\omega(Y)_{n t}=\left(I_{n}-\lambda_{0} W_{n}\right)^{-1}\left[\sum_{k=1}^{K} X_{n t, k} \beta_{0, k}\right]+\left(I_{n}-\lambda_{0} W_{n}\right)^{-1} U_{n t}
$$

According to Pence (2006), two types of impacts can be computed from the reduced form of a model with IHS-transformed dependent variable. Firstly, one can calculate the impacts of a level change of the originally measured dependent variable due to a unit change in an explanatory variable. In the context of spatial autoregressive models, the matrix of marginal impacts for the $k^{\text {th }}$ determinant is

$$
\frac{\partial Y_{n t}}{\partial X_{n t, k}^{\prime}}=\frac{\partial Y_{n t}}{\partial \omega(Y)_{n t}^{\prime}} \frac{\partial \omega(Y)_{n t}}{\partial X_{n t, k}^{\prime}}=\frac{\partial Y_{n t}}{\partial \omega(Y)_{n t}^{\prime}}\left[\left(I_{n}-\lambda_{0} W_{n}\right)^{-1} I_{n} \beta_{0, k}\right]
$$


Referring to Pence (2006), $Y_{n t}$ is the equivalent to the hyperbolic sine of $\omega(Y)_{n t}$. Hence, for individual $i$ at period $t$, we have:

$$
y_{i t}=\frac{1}{2 \theta}\left[e^{\theta_{0} \omega(y)_{i t}}-e^{-\theta_{0} \omega(y)_{i t}},\right]
$$

which implies:

$$
\frac{\partial y_{i t}}{\partial \omega(y)_{i t}}=\frac{1}{2}\left[e^{\theta_{0} \omega(y)_{i t}}+e^{-\theta_{0} \omega(y)_{i t}},\right]
$$

This derivative will differ for different values of $y_{i t}$, a property common to nonlinear models. In equation (10), we construct $\partial Y_{n t} / \partial \omega(Y)_{n t}^{\prime}$, a diagonal matrix where its $i^{\text {th }}$ diagonal element corresponds to $\partial y_{i t} / \partial \omega(y)_{i t}$. To ease the interpretation, we will assess the partial derivative $\partial Y_{n t} / \partial \omega(Y)_{n t}$ at a given value of $y_{i t}$, for instance its median. For this particular case, equation (10) takes the expression shown in equation (11).

$$
\begin{aligned}
& \frac{\partial Y_{n t}}{\partial \omega\left(Y_{n t}\right)^{\prime}}=\frac{1}{2}\left(\begin{array}{ccc}
{\left[e^{\theta_{0} \omega(y)_{1 t}}+e^{-\theta_{0} \omega(y)_{1 t}}\right]} & \cdots & 0 \\
0 & \ddots & \vdots \\
0 & \cdots & {\left[e^{\theta_{0} \omega(y)_{n t}}+e^{-\theta_{0} \omega(y)_{n t}}\right]}
\end{array}\right) \\
& \frac{\partial Y_{n t}}{\partial \omega\left(Y_{n t}\right)^{\prime}}=\frac{1}{2}\left(e^{\theta_{0} \omega\left(y_{m e d}\right)}+e^{-\theta_{0} \omega\left(y_{m e d}\right)}\right) I_{n}
\end{aligned}
$$

where $\omega\left(y_{\text {med }}\right)$ is the dependent variable evaluated at its median value, IHS-transformed. Finally, we obtain the matrix of impacts which measures the effect on the dependent variable (in levels) of a change on the $k^{\text {th }}$ regressor as:

$$
\frac{\partial Y_{n t}}{\partial X_{n t, k}^{\prime}}=S_{n, k}\left(W_{n}\right)=\left(I_{n}-\lambda_{0} W_{n}\right)^{-1} \frac{1}{2}\left[I_{n} \beta_{k, 0}\left(e^{\theta_{0} \omega\left(y_{m e d}\right)}+e^{-\theta_{0} \omega\left(y_{m e d}\right)}\right)\right]
$$

As usual for spatial autoregressive models, this impact matrix is full due to the $\left(I_{n}-\lambda_{0} W_{n}\right)^{-1}$ term. The diagonal elements of $S_{n, k}\left(W_{n}\right)$ represent direct effects, i.e. $\partial y_{i t} / \partial X_{i t, k}$. They are all different from each other due to own-spillover effects, inherently heterogeneous due to differentiated terms in $W_{n}$. This heterogeneity of direct effects is what Debarsy and Ertur (2010) call interactive heterogeneity. Off-diagonal terms of $S_{n, k}\left(W_{n}\right)$ represent indirect effects, $\partial y_{i t} / \partial X_{j t, k}$, i.e. the effect on the dependent variable of observation $i$ due to a change in the $k^{\text {th }}$ regressor of observation $j$.

By contrast to non-spatial models where the impact of a change of a regressor on the dependent variable is a scalar, in spatial autoregressive models we need to interpret a full matrix. To ease interpretations, LeSage and Pace (2009) propose scalar measures which summarize the information contained in impact matrices. They define the average direct effect as $n^{-1} \operatorname{tr}\left(S_{n k}\left(W_{n}\right)\right)$, the average 
cumulated indirect effect as $n^{-1} \iota_{n}^{\prime}\left(S_{n, k}\left(W_{n}\right)-\operatorname{Diag}\left(S_{n, k}\left(W_{n}\right)\right)\right) \iota_{n}$ where $\operatorname{Diag}(A)$ is a diagonal matrix containing the diagonal elements of $\mathrm{A}$, and the average total impact as $n^{-1} \iota_{n}^{\prime}\left(S_{n, k}\left(W_{n}\right)\right) \iota_{n}$.

The average total impact measures the effect on the dependent variable of an observation of a change of the $k^{t h}$ regressor in all observations, or alternatively the average effect on all observations of a change in the $k^{\text {th }}$ regressor in one observation. The average cumulated indirect effect measures the impact on all observations but $i$ of a change in the $k^{\text {th }}$ regressor in observation $i$, or alternatively, the impact on an given observation of a change in the $k^{t h}$ regressor in all observations but the concerned one.

The second type of impacts computation suggested by Pence (2006) consists in calculating the effect of a unit change in the $k^{t h}$ regressor on the percentage change of the dependent variable. This interpretation is akin to that in a specification where the dependent variable is log-transformed. Remembering the link between the IHS and log transformation, this interpretation is valid for large values of the dependent variable. The matrix of partial semi-elasticities for a IHS-transformed SAR specification is presented in equation (13).

$$
\frac{\partial \omega\left(Y_{n t}\right)}{\partial X_{n t, k}^{\prime}}=\left(I_{n}-\lambda_{0} W_{n}\right)^{-1} I_{n} \beta_{k} \approx \frac{1}{\theta_{0}} \frac{\partial \ln \left(Y_{n t}\right)}{\partial X_{n t, k}^{\prime}}
$$

For large values of the dependent variable, the partial derivative of the IHS-transformed dependent variable wrt. the $k^{\text {th }}$ regressor approximates the partial derivative of the log-transformed dependent variable wrt. the same regressor, ignoring a multiplicative factor.

Properties of this impact matrix in terms of direct, indirect and total effects is the same as for equation (12) and the summary scalar measures of LeSage and Pace (2009) can be used.

To draw inference regarding the statistical significance of the scalar summary measures, we follow LeSage and Pace (2009) and construct there distribution using a large number of simulated parameters drawn from the multivariate normal distribution of the parameters implied by the maximum likelihood estimates. ${ }^{5}$ In a second step, we estimate credible confidence intervals for each of the scalar measure of effects.

Expressions (12) and (13) assume a uniform (unit) change in the $k^{\text {th }}$ explanatory variable across target countries (the term $I_{n} \beta_{k}$ in both expressions). However, this homogeneity assumption may be too strong, especially when countries are heterogeneous. Debarsy et al. (2016) propose to consider heterogeneous variations of determinants, which may reflect changes more in line with the real

\footnotetext{
${ }^{5}$ We use 1000 simulations.
} 
world. For instance, if a determinant is more volatile in a first country than in a second, we can expect the determinant change in the first country to be of higher magnitude than in the second. Adapting the notations of Debarsy et al. (2016) to our case, we can extend expressions (12) and (13) to account for heterogeneous changes in the $k^{\text {th }}$ determinant across countries. Expression (14) presents marginal impacts using country specific variation of the $k^{\text {th }}$ determinant:

$$
\frac{\partial Y_{n t}}{\partial X_{n t, k}^{\prime}}=S_{n, k}\left(W_{n}\right)=\left(I_{n}-\lambda_{0} W_{n}\right)^{-1} \frac{1}{2}\left[\Psi_{k} \beta_{k, 0}\left(e^{\theta_{0} \omega\left(y_{m e d}\right)}+e^{-\theta_{0} \omega\left(y_{m e d}\right)}\right)\right]
$$

where $\Psi_{k}$ is a diagonal matrix with as typical diagonal element $\sigma_{k}^{i}$, the historical standard deviation for the $k^{\text {th }}$ determinant of the $i^{\text {th }}$ target country. In this application, the standard deviation is based on observations from 1999 to 2009.

Expression (15) presents semi-elasticities using country specific variation of the $k^{\text {th }}$ determinant:

$$
\frac{\partial \omega\left(Y_{n t}\right)}{\partial X_{n t, k}^{\prime}}=\left(I_{n}-\lambda_{0} W_{n}\right)^{-1} \Psi_{k} \beta_{k}
$$

For economic interpretations based on expressions (14) and (15), we do not use the scalar summary measures of LeSage and Pace (2009) but we rely on a detailed country analysis since impacts are much more heterogeneous across them.

\section{Data and empirical specification}

The regression concerns cross-border SWFs net flows for 43 host countries from 2004 to $2009 .^{6}$ The econometric model to be estimated is a spatial panel data framework with country random effects and the correction of Mundlak and is presented in equation (7). $Y_{n t}$ is the vector of SWFs' cross-border net flows received by the 43 host countries of the sample at period $t$ and $\omega(Y)_{n t}$ is the IHS transformed dependent variable.

One of the main challenge given to the research community on SWF is the lack of official data. Despite the slight improvement over the years, SWFs as most financial investors have remained extremely reluctant to disclose a clear and comprehensive information about their portfolio allocation. In this paper, we construct a novel database on SWF net flows.

For this, we follow Avendano (2010) and Avendano and Santiso (2009) who extract their information from the FactSet/LionShares database ${ }^{7}$. FactSet is a major information source for

\footnotetext{
${ }^{6}$ The considered countries are: Argentina, Australia, Austria, Bahrain, Belgium, Brazil, Canada, Chile, China, Colombia, Czech Republic, Denmark, Egypt, Finland, France, Germany, Greece, Hong Kong, Hungary, Indonesia, Ireland, Israel, Italy, Jordan, Malaysia, Mexico, Morocco, Netherlands, New Zealand, Norway, Peru, Philippines, Poland, Portugal, Russia, Singapore, Spain, Sweden, Switzerland, Thailand, Turkey, United Kingdom, United States.

${ }^{7}$ FactSet aquired LionShares in 2000
} 
institutional ownership and has become over the recent years an important source of information for academic research (see for exemple Guerard et al. (2013)). The construction of the dependent variable is described in Subsection 3.1. The set of considered determinants is described in Subsection 3.2. Finally, the interaction matrices used are described in Subsection 3.3.

\subsection{Dependent variable}

We consider in our dependent variable equity cross-border SWFs net flows amount, excluding investments and divestments made by local SWF in their own country. Amount are expressed in millions of U.S. dollars. The sample consists of 27,968 (resp. 13,490) cross border investments (resp. divestments) in public firms made by the 24 largest SWFs. The total foreign acquisition (resp. sell) flows represents 425.4 (resp. 126.6) billions of U.S. dollars. We are careful to extract investment data for both the SWFs and their subsidiaries, which we define as entities in which SWF has at least a 50\% ownership stake, following the literature (Chhaochharia and Laeven, 2008; Bernstein et al., 2009; Avendano, 2010; Megginson et al., 2013).

The 24 largest SWFs included in our sample hold in 2009 approximatively $\$ 5.93$ trillion, ${ }^{8}$ representing $84 \%$ of total SWF holdings. We restrict our sample to the 2004-2009 period for the sake of homogeneity of our sample as the economic and financial turbulences observed in the aftermath of the Lehman brothers collapse and during the European sovereign debt crisis have dramatically changed the financial environment and the behavior of financial investors. In this respect, our analysis aims to shed light on the driving forces of SWF net flows in normal time.

We transform monthly holding data into share flows (acquisitions or sells) by computing the difference between the number of positions hold by the SWF in a specific company at time $t$ and at time $t-1$. Then, we multiply this quantity by the average stock market price of the target firm for the associated month in order to obtain the amount invested or divested. ${ }^{9}$ Eventually, we aggregate this information across firms, months and SWFs for retrieving the annual net investments per country which is designed to capture the attractiveness of the host countries. Descriptive statistics of our dependent variable are presented in Table 1. At the host country level, we observe in Table 1 both negative and positive net flows amounts, which justifies the use of the IHS transformation.

\footnotetext{
${ }^{8}$ Sovereign Wealth Funds Institute.

${ }^{9}$ We consider the monthly average price instead of the one observed the day of the deal to mitigate the impact of the acquisition or divestment on the stock market price (Fotak et al., 2008; Hesse and Sun, 2009; Dewenter et al., 2010; Raymond, 2010; Fernandes, 2011; Kotter and Lel, 2011; Bortolotti et al., 2013).
} 


\subsection{Explanatory variables}

In this section, we detail the construction of the different explanatory variables used to estimate the model as well as the expected effect on investments' net flows. For the sake of clarity, the set of variables is broken down into two groups: (i) those related to the economic development and (ii) those related to the financial development.

Economic development is described as a sustainable increase in living standards of a certain country or region inhabitants. Improvements in economic development is expected to increase host country attractiveness for capitals. Our set of variables includes first host country 's per capita income, GDPCAP and growth (GDPCAPGWTH). These two variables are expected to increase the net flow of sovereign wealth funds capitals via the so-called wealth effect described in Knill et al. (2012) and Megginson et al. (2013). Following Blonigen et al. (2007), we also include information on skill endowments (SKILL), measured as the average years of schooling for those over age 25 (Barro and Lee, 2001). The variable is only available at a low frequency with observations reported every five years for 1965-2010. For the sake of consistency with the other series, we interpolate linearly the value for the missing years. Domestic investments made by local SWF are added to the model via the variable DOMFLOWS, to test whether cross-border SWFs investments are complementary or substitute to domestic investments. In order to depict the level of economic investment in the host country, we add the variable TOTINV, which is the ratio of the total net investment over GDP (see Table 3). Finally, we include two measures of quality of the economic structure of the host country in our model. The first one, RULELAW, captures the perceptions of the extend to which agents have confidence in and abided by the rules of the society, and particularly in the quality of contract enforcement and property rights. The second one, POLSTAB, assesses the political stability of the country. Those two variables are expected to contribute positively to the country's attractiveness as they depict the quality of the institutional environment for the creditors.

The second set of explanatory variables is related to the financial development of the host country. There are several reasons why better financial development should be beneficial for international investors such as greater credibility, lower transaction costs or higher liquidity to say a few. Three variables are used in the model to capture this dimension of the host economy. First, we consider an indicator measuring the development of the financial intermediary services (FININT), equal to the sum of the liquid liabilities and the domestic credit to private sector over GDP. ${ }^{10}$ We

\footnotetext{
${ }^{10}$ Because of missing data, we linearly interpolated the liquid liabilities variable of 4 countries: Bahrain (2004 and 2007), Canada (2009), Chile (2004 to 2009) and Norway (2007 to 2009) and we interpolated the domestic credit to
} 
expect a positive impact of FININT on SWFs net flows since a sound financial system could make it easier for an economy to absorb capitals from abroad. As second variable, we consider the MSCI growth $(M S C I G W T H)$, which can be adequately summarized as a desire to get into the growing financial market or alternatively to adopt a counter cyclical investment strategy in order to have the opportunity to buy stocks at a lower price ("cheap market effect"). The final financial development variable considered in our regression is the stock market volatility (STKMKTVOL), a measure of uncertainty in financial markets. ${ }^{11}$ As such, we expect a negative impact of the host country volatility on SWFs net flows. Finally, we include in our regression time-effects to account for the presence of macroeconomic shocks. Descriptive statistics of explanatory variables are displayed in Table 2.

As often done in macroeconomic studies, we lag all explanatory variables of one period to mitigate possible endogeneity issues. Table 3 provides more details about the construction of explanatory variables along with the expected effects.

\subsection{Spatial interaction matrices}

Accounting for spatial interactions in SWFs net flows requires the set up of an interaction scheme, modeled through the use of an interaction (spatial weights) matrix $W_{n}$. In this contribution, we use three types of matrices to account for cross-sectional interactions between host nations.

The first considered way of modeling interactions between host countries consists in using geographical neighbors. The associated matrix of interactions is based on the square inverse distance between host countries. To this end, we use the database from the CIA factbook website. In the same spirit of Megginson et al. (2013); Knill et al. (2012); Avendano (2010) and Chhaochharia and Laeven (2008) who analyze the effect of distance between SWF and host nations, we contribute to the existing literature by investigating the effect of distance between host countries themselves on capitals they attract from SWFs. Formally, this geographical interaction matrix is constructed as follows:

$$
w_{i j}=\left\{\begin{array}{lr}
0 & \text { if } \quad i=j \\
\frac{1}{d_{i j}{ }^{2}} & \text { otherwise }
\end{array}\right.
$$

private sector variable for 2 countries: Canada (2009) and Norway (2007 to 2009).

${ }^{11}$ Because of missing data, we linearly interpolated the stock market volatility of 2 countries: Bahrain (2004) and Morocco (2005). 
where $d_{i j}$ is the arc-distance between capitals of countries $i$ and $j$.

As presented in the introduction, interactions between host countries can be justified by the economic closeness between these countries. Therefore, the second interaction scheme used is based on bilateral trade flows. The elements of this matrix are constructed from bilateral monthly imports and exports of host countries from 1998 to 2003 (72 observations), to avoid any endogeneity issues. These bilateral data come from the IMF database and are expressed in USD. More precisely, the interaction between each pair of host countries is constructed as follows:

$$
w_{i j}= \begin{cases}0 & \text { if } i=j \\ \frac{\bar{X}_{i j}+\bar{M}_{i j}}{\bar{X}_{i .}+\bar{M}_{i .}} & \text { otherwise }\end{cases}
$$

where $\bar{X}_{i j}=\frac{1}{T} \sum_{t=1}^{T} X_{i j, t}$ is the average exports over the period from country $i$ to $j, \bar{M}_{i j}=$ $\frac{1}{T} \sum_{t=1}^{T} M_{i j, t}$ represents the average imports of country $i$ from $j, \bar{X}_{i .}=\frac{1}{T} \sum_{t=1}^{T} X_{i, t}$ are the average exports from country $i$ to the rest of the world while $\bar{M}_{i .}=\frac{1}{T} \sum_{t=1}^{T} M_{i, t}$ are the average imports of country $i$ from the rest of the world.

Another argument relative to the high level of concentration of investments in international asset allocation is related to the existence of privileged relationship between home country and host country. The literature on foreign direct investment and international asset allocation emphasizes the critical role of symmetric information (cost) and familiarity in explaining the spatial allocation of international investments (Beugelsdijk and Frijns, 2010). Accordingly, several studies focusing on behavioral arguments for the existence of the home bias as well as over-investment in specific foreign regions have suggested using language proximity as behavioral proxies (Solnik, 2008; Knill et al., 2012; Chhaochharia and Laeven, 2008). Therefore, the third considered interaction matrix is based on this linguistic proximity. The matrix is constructed using the Common Language index (CL) developed by Melitz and Toubal (2014). Their CL index is based on strictly on exogenous linguistic factors and is constructed from three different indexes: Common Official Language (COL), Common Native Language (CNL) and Language Proximity (LP). Their index ranges between 0 and 1. Formally, the elements of this interaction matrix take on the following form:

$$
w_{i j}= \begin{cases}0 & \text { if } i=j \\ C L_{i j} & \text { otherwise }\end{cases}
$$


where $C L_{i j}$ is the Common Language index value between host countries $i$ and $j$.

All interaction matrices are normalized by their spectral radius (see Kelejian and Prucha, 2010). ${ }^{12}$

\section{Results and discussion}

In this section, we identify the factors improving host countries' attractiveness for SWFs' investments as well as the specific role of spatial interactions between host countries regarding their allocation.

Table 4 contains the results of the estimation of model (7). Each column summarizes the results for an interaction matrix. In the first column, we use the geographic distance interaction matrix; in the second column, results are for the economic proximity based interaction matrix while the third column reports the results when interactions are modeled through linguistic proximity. The Wald test on the Mundlak correction variables (Table 4) shows that these control variables are jointly statistically significant, implying a significant correlation between individual effects and regressors.

Estimation results show a negative and significant spatial autoregressive parameter $\lambda$, no matter the interaction matrix used. Economically, such a result finds its justification in the "spatial competition" between countries. Turning to the performance of the different specifications, it is also noticeable that the likelihood value is higher for the linguistic proximity matrix. In the rest of the paper we will therefore interpret the results obtained with this interaction matrix. We also observe that the estimated coefficient of the IHS transformation, $\hat{\theta}$, is significantly different from zero. This means that the transformed dependent variable is more adequate than the original dependent variable to model the data (see MacKinnon and Magee, 1990). For comparison purposes, estimation results using the original dependent variable are presented in Table 5. We first observe a non-significant spatial autoregressive parameter, no matter the interaction matrix used. Besides, we loose the significance of all but the stock market volatility and the skill variable. We also note that the coefficient associated to the skill variable switched of sign. We finally remark that the constant term becomes significant.

Figure 2 shows the distribution of the IHS transformed SWFs net flows amounts with $\widehat{\theta}=0.042$, coming from the estimation of the model with the linguistic proximity interaction matrix (see Table 4). We notice that the distribution of this variable looks much more like a normal distribution

\footnotetext{
${ }^{12}$ Interaction matrices are normalized to ensure the comparability of spatial autoregressive parameters coming from different models.
} 
than the distribution of the original dependent variable, shown in Figure 1.

To analyze the effects of the determinants on SWFs net flows, we first rely on the marginal impacts or semi-elasticities given by expressions (12) and (13) respectively and reported in Tables 6 and 7 for the linguistic proximity interaction matrix. ${ }^{13}$ These impacts assume an homogeneous variation of determinant across countries To save on space, we only interpret the results in terms of semi-elasticities, reported in Table 7.

Concerning direct impacts, we provide evidence that on average, SWFs net flows increase with DOMFLOWS, GDPCAP, POLSTAB and FININT and decrease with SKILL and STKMKTVOL.

The positive direct effect of DOMFLOWS implies that domestic investments by local SWFs are not made at the expense of foreign investments but act more as a complement. The findings regarding to GDPCAP and FININT show that more mature economies - i.e. economies with higher GDP per capita and sound financial market - tend to attract more investments. Political stability of the host country is also a factor that positively contributes to the attractiveness. Conversely, increased uncertainty in the financial environment as measured by high volatility in the local stock market dampens SWF net flows. Eventually, everything been equal, countries with low skills workers attract more capitals.

We now turn to the indirect impacts. These impacts measure the response of a change in a determinant of one country on the SWF net flows in all other countries except the one in which the variation has been implemented. Due to negative interactions between host countries, their sign will be opposite to those obtained for direct effects. We note that the average indirect effects associated to DOMFLOWS, GDPCAP, POLSTAB, SKILL, and FININT are statistically significant implying that a variation in one of these variable in a country will affect SWF investment flows in all other countries.

The presence of significant indirect effects supports the idea externatilities among receiving countries : changes in the characteristics of a country has implications for the flows of capitals of others as investors tend to reallocate their portfolios in reponse to financial and economic developments. Contrasting with other variables, it is worth noting that even though STKMKTVOL has a significant negative direct effect on the attraction of SWFs capital, this variable does not have any significant indirect effect.

\footnotetext{
${ }^{13}$ Marginal impacts and semi-elasticities for the geographic and economic proximity interaction matrices are quantitatively and quantitatively similar to those obtained with the linguistic proximity interaction matrix and are available upon request to the authors.
} 
Finally, we observe significant total effects for DOMFLOWS, SKILL, POLSTAB GDPCAP, FININT and STKMKTVOL. The sign of these total effects are the same as those of direct effects, but semi-elasticities are of lower magnitude, due to the dampening effect of indirect impacts.

Using country specific variations in the determinants, and thus relying on expressions (14) and (15), we now report a more detailed analysis by investigating the direct and indirect semielasticities of the FININT variable that is the one assessing the quality of financial intermediary services infrastructure for each country. ${ }^{14}$ We also compare these results with those obtained assuming homogeneous variation across target countries.

Figure 3 reports the direct semi-elasticities of the FININT variables for each country, assuming an homogeneous unit increase of FININT. Even though these direct effects are theoretically heterogeneous, in this paper, we do not observe much heterogeneity between countries. However, in Figure 4, which represents direct semi-elasticities of an heterogeneous variation of FININT across target countries, we observe a much higher heterogeneity, with the biggest impacts for Spain, Ireland and Denmark. In other words, these three countries are the most reactive in terms of investments from SWFs when their financial intermediary services vary. For instance, increasing Spanish FININT by one percentage point leads to an increase in net investments from SWFs in Spain of 1.68\%. By contrast, in the homogeneous case, Norway, Sweden and Italy were the most reactive countries to a change in their financial intermediary services. At the other end, we note that Mexico and Indonesia have the smallest direct impact ( $0.009 \%$ for both) meaning that investments from SWF's in these country are the least reactive to a change in their FININT determinant.

One of the most interesting features of these interaction models concerns the explicit accounting of indirect effects. Indeed, in the SAR model, affecting a determinant in a selected country will affect SWF's investment in all other countries. This characteristic is very important since we are able to account for externalities due to a policy change in a country.

As for direct effects, we compare indirect semi-elasticities assuming either an homogeneous or an heterogeneous variation in FININT. Figure 5 shows the cumulated indirect semi-elasticities for each country assuming an homogeneous increase in FININT. As noted earlier, indirect effects are negative since target countries are characterized by spatial competition. In this Figure, we already note some heterogeneity: Countries that affect the least other countries are China and Hong-Kong while variation in FININT in Norway, Sweden or Italy will affect the most all other countries.

\footnotetext{
${ }^{14}$ For the sake of place, we only focus on the FININT variable. However, all the results for all the other variables and for the marginal impacts are available upon request to the authors.
} 
Figure 6 shows indirect semi-elasticities based on an heterogeneous variation of FININT across target countries. Two main points need to be made. First, we observe a much pronounced heterogeneity in these indirect semi-elasticities. While those based on homogeneous change in FININT vary between -0.01 and -0.001 , indirect semi-elasticities constructed from countries' specific FININT changes vary between $-0.433 \%$ and $-0.005 \%$. Second, countries with the highest cumulated indirect effects are different. For the heterogeneous case, these are Denmark $(-0.433 \%)$, Netherlands $(-0.354 \%)$ and Spain $(-0.296 \%)$. These figures imply for instance that if the Danish FININT increases by one standard deviation, the cumulated net divestments in all other countries in the sample will be of $0.433 \%$. In the homogeneous case, these countries are Norway, Sweden and Italy. Also, countries for which changes in FININT affect the least all the other countries are Indonesia (-0.005\%) and Philippines (-0.007\%).

Indirect semi-elasticities based on countries' specific changes allow to assess more realistically the impact of a change in a country's determinant on the whole system, since the impact accounts for the nature of the country (stable or unstable determinant). We believe these impacts are quite useful for macroeconomic analysis.

\section{Conclusions}

This paper aims to shed light on the question of why some countries are more attractive for SWFs cross-border investments than others and whether target countries sharing similarities are set in competition to receive these capitals. To do so, we develop an original framework that quantifies the specific role of spatial dependence in the location of SWFs' investments on one side and on the other side is robust to outliers while dealing with zero and negative values of investments thanks to the Inverse Hyperbolic Sine transformation to the dependent variable. More specifically, the estimation procedure we propose is a random effects spatial autoregressive panel model with an Inverse Hyperbolic Sine transformed dependent variable, where the possible correlation between individual effects and regressors is accounted for through the use of the Mundlak approach. Three interaction schemes are considered to model interactions between host countries. The first one is based on geographic distance. The second one is the economic proximity which is captured by the relative intensity of bilateral trade between countries. The third one reflects linguistic proximity. Several insights emerge from our analysis. Hence, these results suggest that country-level variables can affect sovereign wealth fund net flows and thereby potentially help contribute to growth. Coun-

tries with higher GDP per capita and Domestic flows tend to attract more SWFs capital. SWFs 
net flows also appear to depend on the level of the financial development captured by the ratio of financial resources to the private sector over GDP. Besides, better political stability and higher level of financial development of host country contribute positively to SWF's investments net flows, while stock market volatility has the opposite effect. Beyond that, at the system wide level, our findings additionally show that these effects should not be considered in isolation. The spatial autoregressive parameter is negative and significant for the three interaction matrices. In accordance, there will be multilateral consequences in changes in countries characteristics, as investors tend to reallocate their portfolios in response to financial and economic developments in neighbors countries. The results are consistent with arguments that countries with close economic tights or those sharing cultural similarities are set in competition. One way to interpret this result is that once having the necessary information to invest in a bunch of neighboring countries, investors tend to concentrate their investment in the one providing the most interesting perspectives. That being said, this paper by taking the perspective of the host country does not provide a full insight of the mechanisms at play and especially of how each sovereign wealth funds behave individually. This issue and the necessary adjustment of the spatial models to be used in this case are left for future research. Still, we make clear that the analysis of sovereign wealth funds net flows should take into account country characteristics but also the externalities to other countries. From an econometric perspective, the key insight from this paper is that we can adjust standard panel and spatial panel model estimation procedure to apply of the IHS transformation. As discussed throughout the paper, this transformation is very convenient to deal with the presence of outliers as well as null and negative values of the dependent variable. There are obviously many research in macroeconomics and finance such as modeling of foreign direct investment and trade that could benefit from this transformation and the associated estimation procedure we propose. 
Avendaño R, Santiso J. 2009. Are sovereign wealth funds' investments politically biased? a comparison with mutual funds. OECD Working paper.

Avendano R. 2010. Sovereign wealth fund investments: From firm-level preferences to natural endowments. Working paper, Paris School of Economics.

Aviat A, Coeurdacier N. 2007. The geography of trade in goods and asset holdings. Journal of International Economics 71: 22-51.

Barro R, Lee JW. 2001. International data on educational attainment updates and implications. Economic Papers 53: 541-563.

Bénassy-Quéré A, Coupet M, Mayer T. 2007. Institutional determinants of foreign direct investment. The World Economy 30: 764-782.

Bernstein S, Lerner J, , Schoar A. 2009. The investment strategies of sovereign wealth funds. NBER Working paper.

Beugelsdijk S, Frijns B. 2010. A cultural explanation of the foreign bias in international asset allocation. Journal of Banking $\mathscr{G}$ Finance 34: 2121-2131.

Bickel P, Doksum K. 1981. An analysis of transformations revisited. Journal of the American Statistical Association 76: 296-311.

Blonigen B, Davies R, Waddell G, Naughton H. 2007. Fdi in space: Spatial autoregressive relationships in foreign direct investment. European Economic Review 51: 1303-1325.

Bortolotti B, Fotak V, Megginson WL. 2013. The sovereign wealth fund discount: Evidence from public equity investments. Baffi Center Research Paper.

Breusch TS. 1987. Maximum likelihood estimation of random effects models. Journal of Econometrics 36: 383-389.

Burbidge JB, Magee L, Robb AL. 1988. Alternative transformations to handle extreme values of the dependent variable. Journal of the American Statistical Association 83: 123-127.

Carroll C, Dynan KE, Krane S. 2003. Unemployment risk and precautionary wealth: Evidence from households' balance sheets. Review of Economics and Statistics 85: 586-604. 
Chhaochharia V, Laeven L. 2008. Sovereign wealth funds: Their investment strategies and performance. Discussion Paper 6959, C.E.P.R.

Debarsy N. 2012. The mundlak approach in the spatial durbin panel data model. Spatial Economic Analysis 7: 109-131.

Debarsy N, Ertur C. 2010. Testing for spatial autocorrelation in a fixed effects panel data model. Regional Science and Urban Economics 40: 453-470.

Debarsy N, Dossougoin C, Ertur C., Gnabo JY., 2016. Assessing the role of transmission channels in sovereign risk: A spatial econometrics approach, Working paper.

Demirguc-Kunt A, Levine R. 1996. Stock market development and financial intermediaries: Stylized facts. World Bank Economic Review 10: 291-321.

Dewenter KL, Han X, Malatesta P. 2010. Firm values and sovereign wealth fund investments. Journal of Financial Economics 98: 256-278.

Disdier AC, Head K. 2008. The puzzling persistence of the distance effect on bilateral trade. The Review of Economics and statistics 90: 37-48.

Eaton J, Tamura A. 1994. Bilateralism and regionalism in japanese and us trade and direct foreign investment patterns. Journal of the Japanese and international economies 8: 478-510.

Fernandes N. 2011. Sovereign wealth funds: Investment choices and implications around the world. Working paper.

Fotak V, Bortolotti B, Megginson W, Miracky W. 2008. The financial impact of sovereign wealth fund investments in listed companies. Working paper.

Frankel JA, Stein E, Wei SJ. 1997. Regional trading blocs in the world economic system. Peterson Institute.

Guerard JB, Markowitz H, Xu G. 2013. Global stock selection modeling and efficient portfolio construction and management. The Journal of Investing 22: 121-128.

Hau H. 2001. Location matters: An examination of trading profits. Journal of Finance 56: 19591983. 
Hesse H, Sun T. 2009. Sovereign wealth funds and financial stability-an event study analysis. IMF Working paper 9: 239.

John J, Draper NR. 1980. An alternative family of transformations. Journal of the Royal Statistical Society, Serie C 29: 190-197.

Johnson NL. 1949. Systems of frequency curves generated by methods of translation. Biometrika : 149-176.

Kapteyn A, Panis C. 2003. The size and composition of wealth holdings in the united states, italy, and the netherlands. NBER Working paper 10182.

Karolyi G, Liao RC. 2010. What is different about government-controlled acquirers in cross-border acquisitions? Working paper University of Cornell.

Kelejian HH, Prucha IR. 2010. Specification and estimation of spatial autoregressive models with autoregressive and heteroskedastic disturbances. Journal of Econometrics 157: 53-67.

Kennickell AB, Sunden AE. 1997. Pensions, social security, and the distribution of wealth. Federal Reserve Board of Governors. Finance and Economics Discussion Series 55: 1-41.

Knill A, Lee BS, Mauck N. 2012. Bilateral political relations and sovereign wealth fund investment. Journal of Corporate Finance 18: 108-123.

Kotter J, Lel U. 2011. Friends or foes? target selection decisions of sovereign wealth funds and their consequences. Journal of Financial Economics 101: 360-381.

Kristjánsdóttir H. 2005. Determinants of foreign direct investment in iceland. Working paper.

Lee LF, Yu J. 2010a. Estimation of spatial autoregressive panel data models with fixed effects. Journal of Econometrics 154: 165-185.

Lee LF, Yu J. 2010b. Some recent developments in spatial panel data models. Regional Science and Urban Economics 40: 255-271.

Lee LF, Yu J. 2012. Spatial panel: random components versus fixed effects. International Economic Review 53: 1369-1412.

LeSage J, Pace RK. 2009. Introduction to spatial econometrics. CRC Press Taylor and Francis Group. 
Lin X, Lee LF. 2010. GMM estimation of spatial autoregressive models with unknown heteroskedasticity. Journal of Econometrics 157: 34-52.

Linders GJ, De Groot HL. 2006. Estimation of the gravity equation in the presence of zero flows. Working paper.

MacKinnon J, Magee L. 1990. Transforming the dependent variable in regression models. International Economic Review 31: 315-39.

Megginson WL, You M, Han L. 2013. Determinants of sovereign wealth fund cross-border investments. The Financial Review 48: 539-572.

Megginson WL, Fotak V. 2014. Rise of the fiduciary state: A survey of sovereign wealth fund research. Working paper available at SSRN 2432623.

Melitz J, Toubal F. 2014. Native language, spoken language, translation and trade. Journal of International Economics 93: 351-363.

Mundlak Y. 1978. On the pooling of time series and cross section data. Econometrica 46: 69-85.

Pence KM. 2006. The role of wealth transformations: An application to estimating the effect of tax incentives on saving. Contributions in Economic Analysis $\&$ Policy 5: 1-24.

Portes R, Rey H. 2005. The determinants of cross-border equity flows. Journal of international Economics 65: 269-296.

Raballand G. 2003. Determinants of the negative impact of being landlocked on trade: an empirical investigation through the central Asian case. Comparative Economic Studies 45: 520-536.

Raymond H. 2010. Sovereign wealth funds as domestic investors of last resort during crises. International Economics 123: 121-160.

Reynolds A, Shonkwiler J. 1991. Testing and correcting for distributional misspecifications in the tobit model: An application of the information matrix test. Empirical Economics 16: 313-23.

Solnik B. 2008. Equity home bias and regret: An international equilibrium model. Working paper available at SSRN 828405. 
Wansbeek T, Kapteyn A. 1982. A class of decompositions of the variance-covariance matrix of a generalized error components model. Econometrica: Journal of the Econometric Society : $713-724$.

Yen ST, Jones A. 1997. Household consumption of cheese: An inverse hyperbolic sine double-hurdle model with dependent errors. American Journal of Agricultural Economics 79: 246-251.

Yu J, Walsh JP. 2010. Determinants of foreign direct investment; a sectoral and institutional approach. IMF Working paper 10: 87.

Zhang J. 2014. Foreign direct investment, governance, and the environment in China: Regional dimensions. Palgrave Macmillan. 
Table 1: Descriptive Statistics of the dependent variable (\$ MM).

\begin{tabular}{lcccc||lcccc}
\hline Country & Average & Std. & Min & Max & Country & Average & Std. & Min & Max \\
\hline Argentina & 2.21 & 4.36 & -1.13 & 10.70 & Italy & 701.52 & 607.87 & 141.73 & 1482.09 \\
Australia & 572.99 & 774.37 & -270.75 & 1905.39 & Jordan & -224.90 & 1697.16 & -3532.56 & 1154.33 \\
Austria & -542.52 & 1495.04 & -3558.52 & 271.56 & Malaysia & 627.67 & 768.54 & -693.08 & 1532.99 \\
Bahrain & 123.63 & 188.00 & -35.29 & 470.27 & Mexico & 169.89 & 518.59 & -715.90 & 602.33 \\
Belgium & 317.02 & 225.49 & 123.57 & 595.56 & Morocco & 2.79 & 6.90 & -0.72 & 16.84 \\
Brazil & 550.07 & 650.10 & -74.66 & 1757.37 & Netherlands & 352.82 & 552.07 & -340.57 & 1286.46 \\
Canada & 1272.35 & 1413.31 & 277.52 & 4090.62 & New Zealand & 10.43 & 23.41 & -28.17 & 34.47 \\
Chile & 22.17 & 74.06 & -67.39 & 152.82 & Norway & 18.95 & 32.67 & -3.23 & 82.65 \\
China & 1775.50 & 3400.16 & -3093.65 & 6434.96 & Peru & 4.05 & 12.42 & -5.37 & 28.87 \\
Colombia & 2.03 & 4.53 & -0.56 & 11.22 & Philippines & 16.14 & 22.51 & -2.54 & 55.27 \\
Czech Republic & 32.99 & 135.99 & -159.62 & 258.97 & Poland & 51.99 & 134.19 & -50.37 & 319.01 \\
Denmark & 411.80 & 896.63 & -878.44 & 1770.00 & Portugal & 185.66 & 257.39 & -98.61 & 551.87 \\
Egypt & -3.48 & 1054.45 & -1772.92 & 1487.32 & Russia & 8150.54 & 18098.23 & -999.35 & 44940.69 \\
Finland & 381.68 & 432.02 & 42.55 & 1062.37 & Singapore & 79.72 & 101.22 & -51.79 & 186.42 \\
France & 2172.24 & 2755.57 & -1658.63 & 6293.18 & Spain & 788.20 & 1134.91 & -502.92 & 2509.58 \\
Germany & 4208.06 & 4144.35 & 388.17 & 11182.65 & Sweden & 441.16 & 401.93 & -302.48 & 927.05 \\
Greece & 117.71 & 124.42 & -8.07 & 327.54 & Switzerland & 3760.68 & 3205.73 & 1260.00 & 9891.49 \\
Hong Kong & 734.85 & 1328.26 & 52.13 & 3422.90 & Thailand & 345.78 & 671.99 & -513.81 & 1468.03 \\
Hungary & 44.47 & 147.00 & -114.71 & 303.92 & Turkey & 124.52 & 210.30 & -24.85 & 500.61 \\
Indonesia & -303.27 & 1324.47 & -2977.83 & 579.24 & UK & 6549.32 & 6699.62 & 471.87 & 15066.14 \\
Ireland & 64.64 & 201.14 & -153.66 & 285.79 & USA & 15625.00 & 13656.56 & 6089.76 & 37272.06 \\
Israel & 58.58 & 107.17 & -26.19 & 266.05 & & & & & \\
\hline \hline & & & & & & & & & \\
\hline
\end{tabular}

Table 2: Descriptive Statistics for explanatory variables

\begin{tabular}{lcccc}
\hline & Average & Std. & Min & Max \\
\hline DOMFLOWS (\$ bil.) & 0.21 & 1.32 & -1.68 & 14.14 \\
GDPCAP (\$ M.) & 22.56 & 17.96 & 1.12 & 67.80 \\
GDPCAPGWTH (\%) & 3.10 & 2.64 & -4.58 & 13.57 \\
POLSTAB $(* 100)$ & 21.83 & 93.44 & -239.00 & 166.00 \\
RULELAW $(* 100)$ & 80.88 & 94.01 & -95.00 & 200.00 \\
SKILL $(* 100)$ & 958.85 & 227.23 & 357.60 & 1330.46 \\
TOTINVT (\%) & 23.28 & 4.79 & 14.26 & 43.78 \\
FININT (\%) & 173.08 & 87.36 & 37.57 & 434.77 \\
MSCIGWTH $(\%)$ & 3.51 & 11.50 & -36.78 & 25.20 \\
STKMKTVOL & 19.52 & 7.40 & 7.56 & 44.96 \\
\hline
\end{tabular}




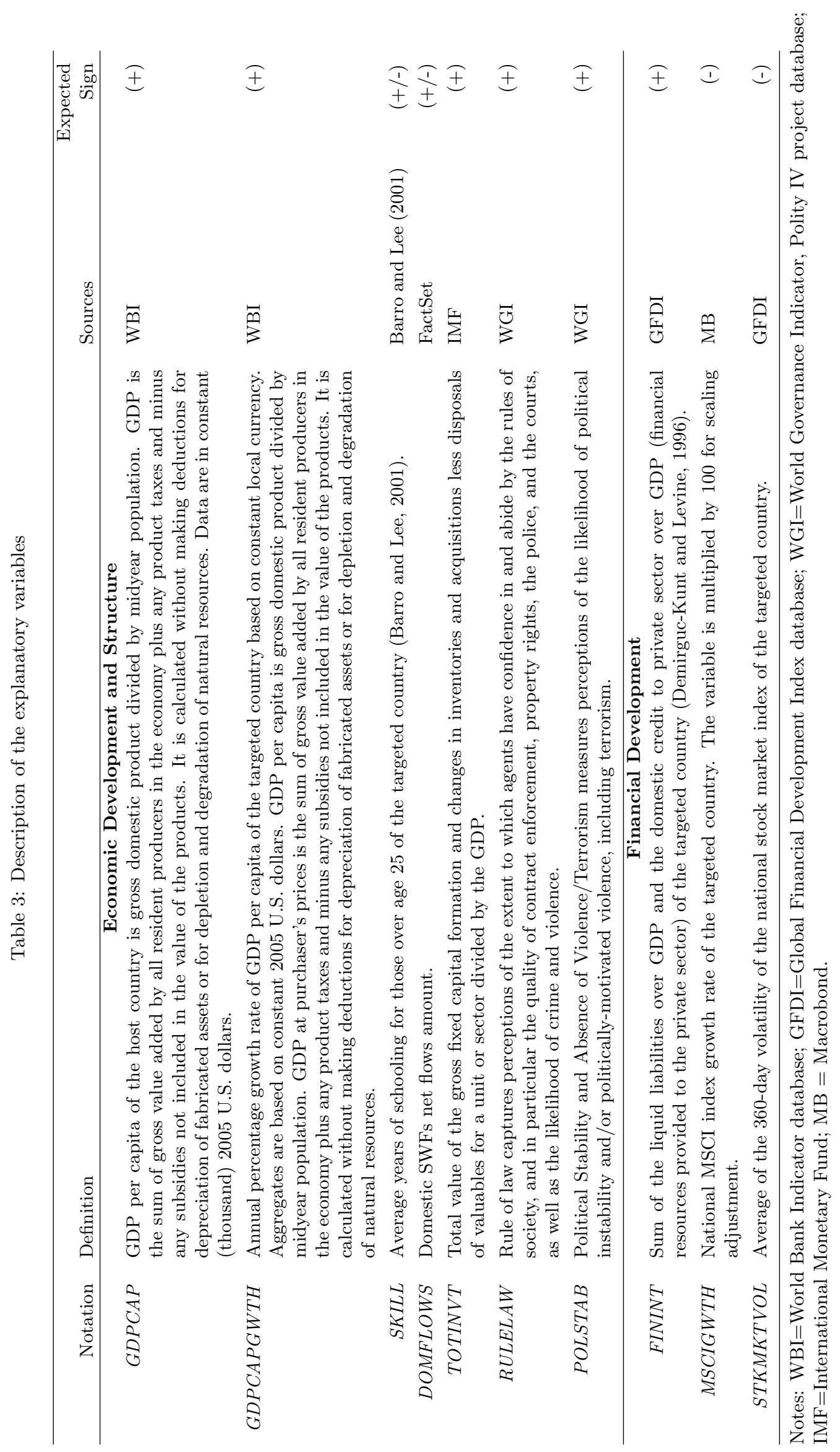


Table 4: Results using IHS-transformed SWFs net flows amounts

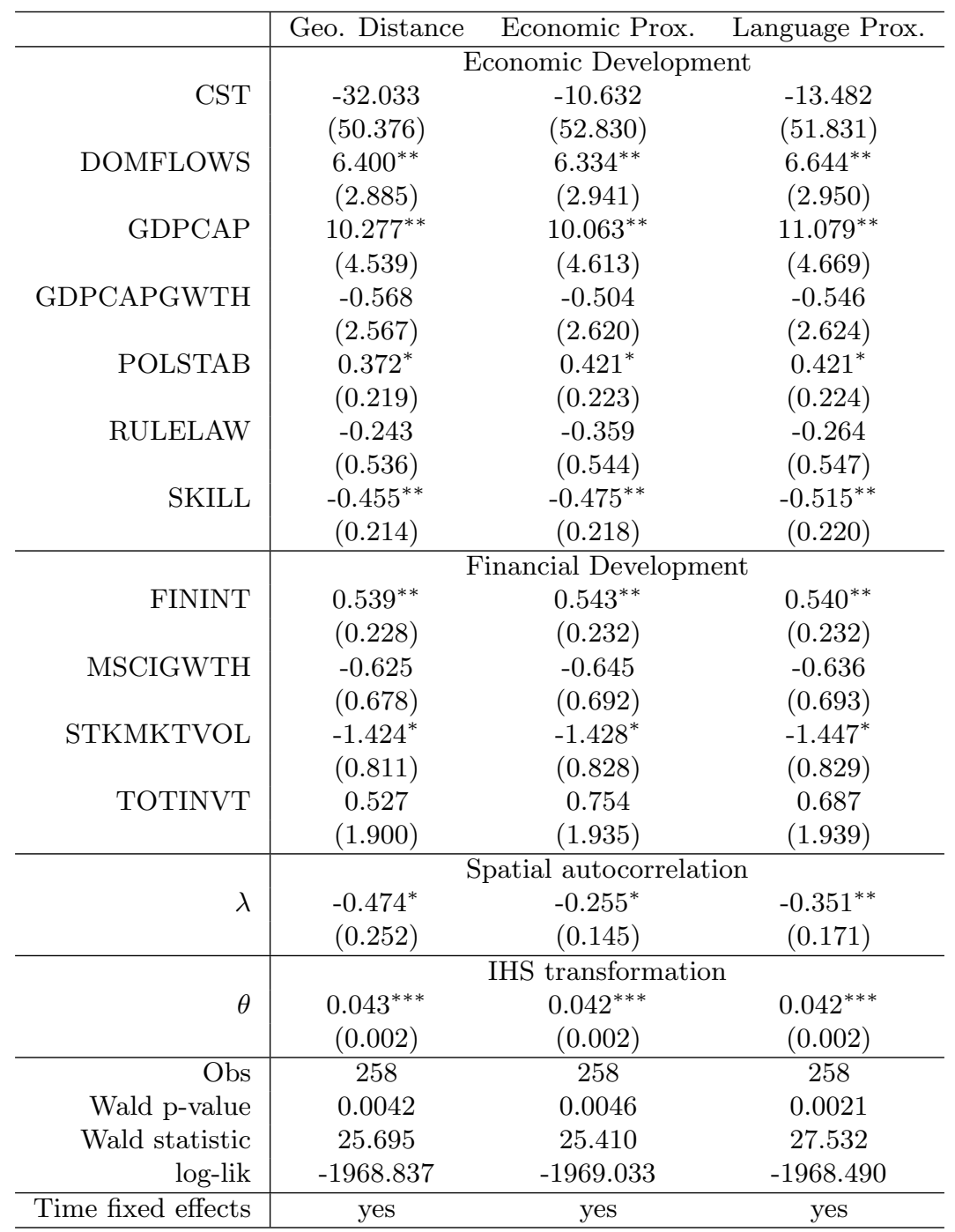

Notes: $* * *, * *$ and $*$ indicate significance level at the $1 \%, 5 \%$ and $10 \%$ level. Standard errors reported between brackets. 
Table 5: Results using original SWFs net flows amounts

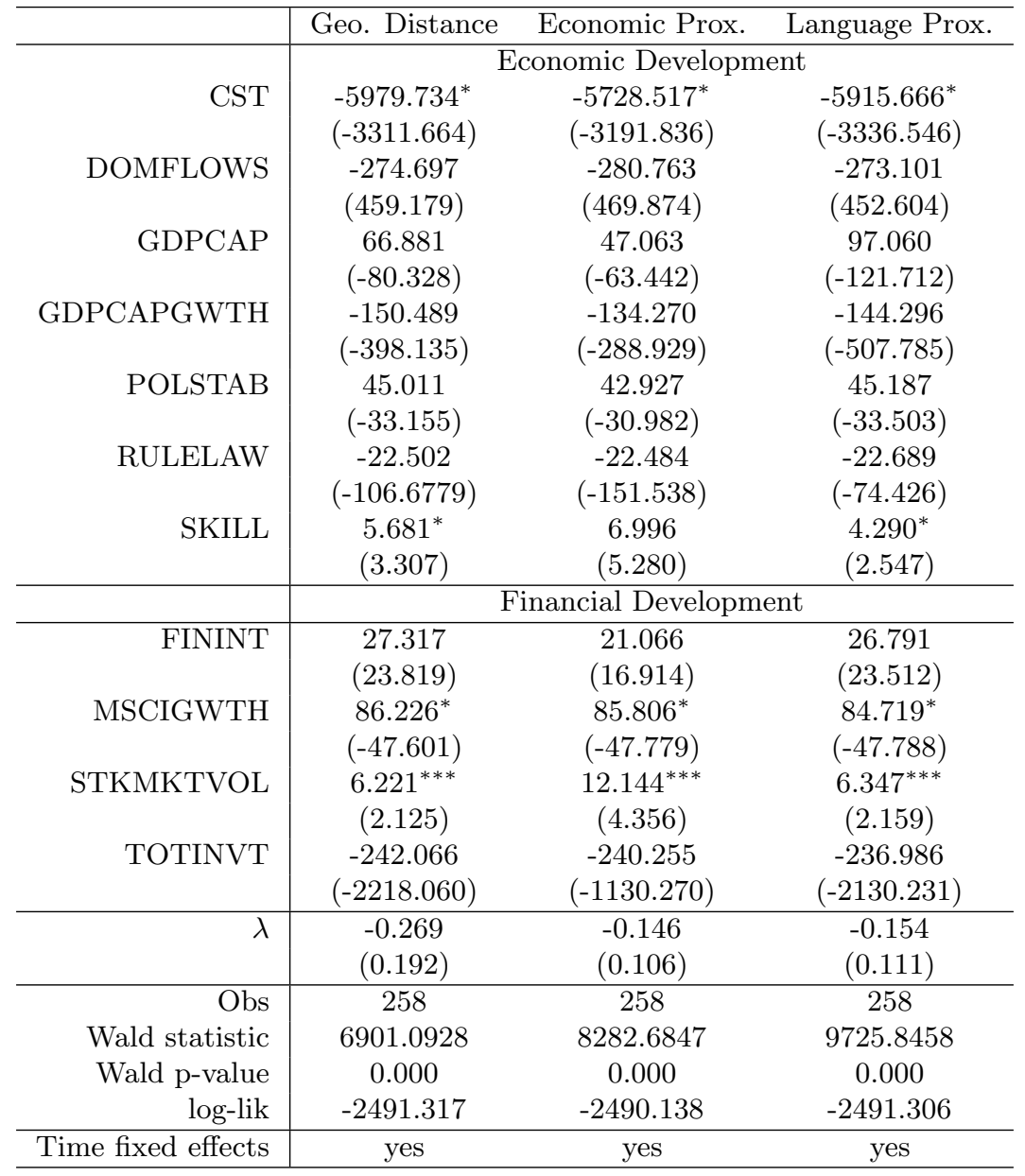

Notes: $* * *, * *$ and $*$ indicate significance level at the $1 \%, 5 \%$ and $10 \%$ level. Standard errors reported between brackets. 
Table 6: Average Impacts on SWFs net flows amounts (\$ Millions), evaluated at median (\$125.64 Millions)

\begin{tabular}{|c|c|c|c|}
\hline & Direct Impact & $\begin{array}{l}\text { Language Prox. } \\
\text { Indirect Impact }\end{array}$ & Total Impact \\
\hline & \multicolumn{3}{|c|}{ Economic Development } \\
\hline \multirow[t]{2}{*}{ DOMFLOWS } & $35.746^{* *}$ & $-5.795^{* *}$ & $29.952^{* *}$ \\
\hline & $(9.349 ; 62.781)$ & $(-11.935 ;-0.686)$ & $(7.965 ; 53.042)$ \\
\hline \multirow[t]{2}{*}{ GDPCAP } & $59.608^{* *}$ & $-9.663^{* *}$ & $49.945^{* *}$ \\
\hline & $(19.457 ; 101.582)$ & $(-20.851 ;-0.975)$ & $(16.433 ; 84.561)$ \\
\hline \multirow[t]{2}{*}{ GDPCAPGWTH } & -2.939 & 0.477 & -2.463 \\
\hline & $(-23.957 ; 19.701)$ & $(-3.567 ; 4.122)$ & $(-20.506 ; 16.035)$ \\
\hline \multirow[t]{2}{*}{ POLSTAB } & $2.267^{*}$ & $-0.368^{*}$ & $1.9^{*}$ \\
\hline & $(0.31 ; 4.112)$ & $(-0.808 ;-0.008)$ & $(0.24 ; 3.563)$ \\
\hline \multirow[t]{2}{*}{ RULELAW } & -1.421 & 0.23 & -1.191 \\
\hline & $(-6.222 ; 3.468)$ & $(-0.597 ; 1.112)$ & $(-5.239 ; 2.882)$ \\
\hline \multirow[t]{3}{*}{ SKILL } & $-2.771^{* *}$ & $0.449^{*}$ & $-2.322^{* *}$ \\
\hline & $(-4.647 ;-0.788)$ & $(0.042 ; 0.948)$ & $(-3.865 ;-0.659)$ \\
\hline & \multicolumn{3}{|c|}{ Financial Development } \\
\hline \multirow[t]{2}{*}{ FININT } & $2.905^{* *}$ & $-0.471^{* *}$ & $2.434^{* *}$ \\
\hline & $(0.945 ; 4.867)$ & $(-0.981 ;-0.05)$ & $(0.802 ; 4.119)$ \\
\hline \multirow[t]{2}{*}{ MSCIGWTH } & -3.424 & 0.555 & -2.869 \\
\hline & $(-9.436 ; 2.57)$ & $(-0.426 ; 1.746)$ & $(-7.921 ; 2.146)$ \\
\hline \multirow[t]{2}{*}{ STKMKTVOL } & $-7.783^{*}$ & 1.262 & $-6.521^{*}$ \\
\hline & $(-15.434 ;-0.23)$ & $(-0.045 ; 2.83)$ & $(-13.37 ;-0.172)$ \\
\hline \multirow[t]{2}{*}{ TOTINVT } & 3.695 & -0.599 & 3.096 \\
\hline & $(-14.292 ; 20.162)$ & $(-3.609 ; 2.383)$ & $(-11.704 ; 16.853)$ \\
\hline
\end{tabular}

$* * *, * *$ and $*$ indicate significance level at the $1 \%, 5 \%$ and $10 \%$

level. $10 \%$ confidence interval reported between brackets. 
Table 7: Semi-Elasticities (\%)

\begin{tabular}{|c|c|c|c|}
\hline & Direct Impact & $\begin{array}{l}\text { Language Prox. } \\
\text { Indirect Impact }\end{array}$ & Total Impact \\
\hline & \multicolumn{3}{|c|}{ Economic Development } \\
\hline \multirow[t]{2}{*}{ DOMFLOWS } & $0.280^{* *}$ & $-0.045^{* *}$ & $0.234^{* *}$ \\
\hline & $(0.073 ; 0.491)$ & $(-0.093 ;-0.005)$ & $(0.062 ; 0.414)$ \\
\hline \multirow[t]{2}{*}{ GDPCAP } & $0.466^{* *}$ & $-0.076^{* *}$ & $0.391^{* *}$ \\
\hline & $(0.152 ; 0.794)$ & $(-0.163 ;-0.008)$ & $(0.128 ; 0.661)$ \\
\hline \multirow[t]{2}{*}{ GDPCAPGWTH } & -0.023 & 0.004 & -0.019 \\
\hline & $(-0.187 ; 0.154)$ & $(-0.028 ; 0.032)$ & $(-0.16 ; 0.125)$ \\
\hline \multirow[t]{2}{*}{ POLSTAB } & $0.018^{*}$ & $-0.003^{*}$ & $0.015^{*}$ \\
\hline & $(0.002 ; 0.032)$ & $(-0.006 ;-0.0001)$ & $(0.002 ; 0.028)$ \\
\hline \multirow[t]{2}{*}{ RULELAW } & -0.011 & 0.002 & -0.009 \\
\hline & $(-0.049 ; 0.027)$ & $(-0.005 ; 0.009)$ & $(-0.041 ; 0.023)$ \\
\hline \multirow[t]{3}{*}{ SKILL } & $-0.022^{* *}$ & $0.004^{*}$ & $-0.018^{* *}$ \\
\hline & $(-0.036 ;-0.006)$ & $(0.0003 ; 0.007)$ & $(-0.03 ;-0.005)$ \\
\hline & \multicolumn{3}{|c|}{ Financial Development } \\
\hline \multirow[t]{2}{*}{$\overline{\text { FININT }}$} & $0.023^{* *}$ & $-0.004^{* *}$ & $0.019^{* *}$ \\
\hline & $(0.007 ; 0.038)$ & $(-0.008 ;-0.0004)$ & $(0.006 ; 0.032)$ \\
\hline \multirow[t]{2}{*}{ MSCIGWTH } & -0.027 & 0.004 & -0.022 \\
\hline & $(-0.073 ; 0.02)$ & $(-0.003 ; 0.014)$ & $(-0.062 ; 0.017)$ \\
\hline \multirow[t]{2}{*}{ STKMKTVOL } & $-0.061^{*}$ & 0.01 & $-0.051^{*}$ \\
\hline & $(-0.12 ;-0.002)$ & $(-0.0004 ; 0.022)$ & $(-0.104 ;-0.001)$ \\
\hline \multirow[t]{2}{*}{ TOTINVT } & 0.029 & -0.005 & 0.024 \\
\hline & $(-0.112 ; 0.158)$ & $(-0.028 ; 0.019)$ & $(-0.091 ; 0.131)$ \\
\hline
\end{tabular}

Notes: $* * *, * *$ and $*$ indicate significance level at the $1 \%, 5 \%$ and $10 \%$ level. $10 \%$ confidence interval reported between brackets. 


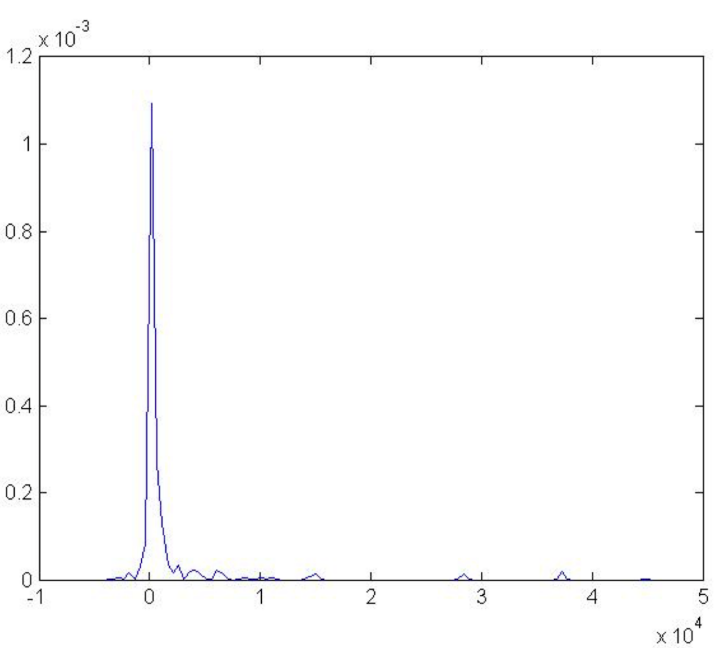

Figure 1: Foreign SWFs net flows amount

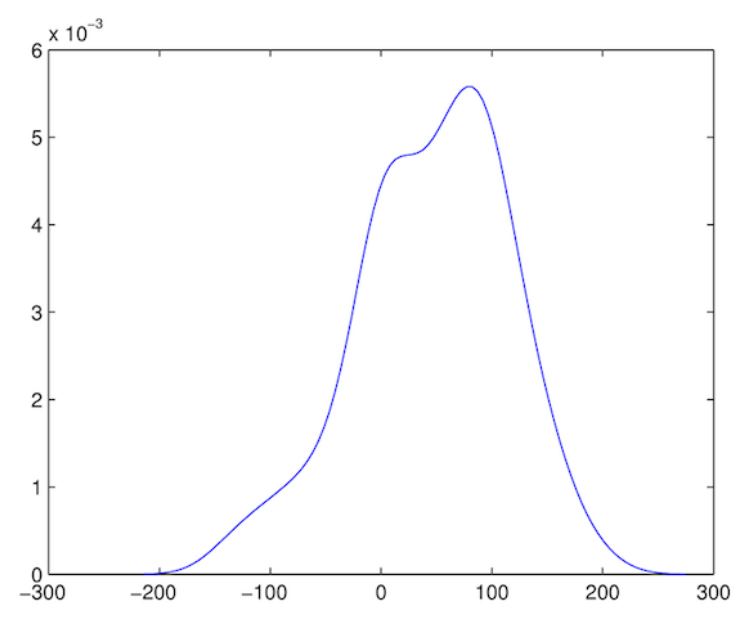

Figure 2: Foreign SWFs net flows amounts IHS transformed with $\hat{\theta}=0.0420$ 


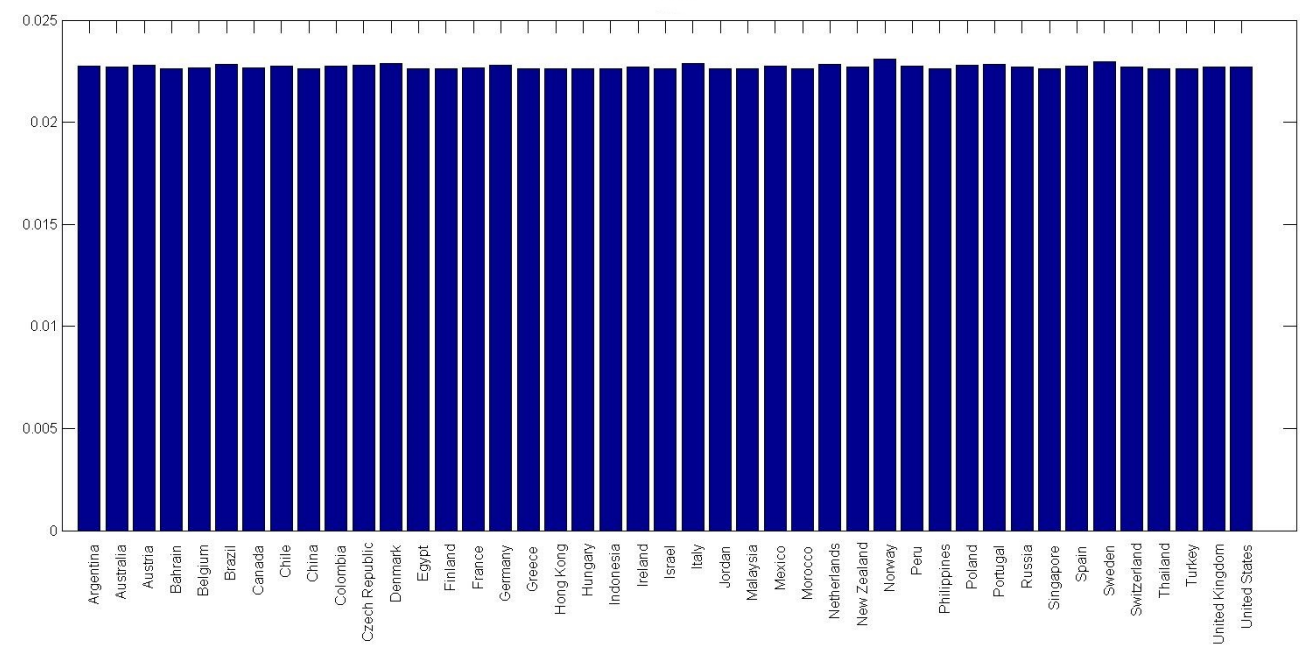

Figure 3: Standard direct semi-elasticities for FININT

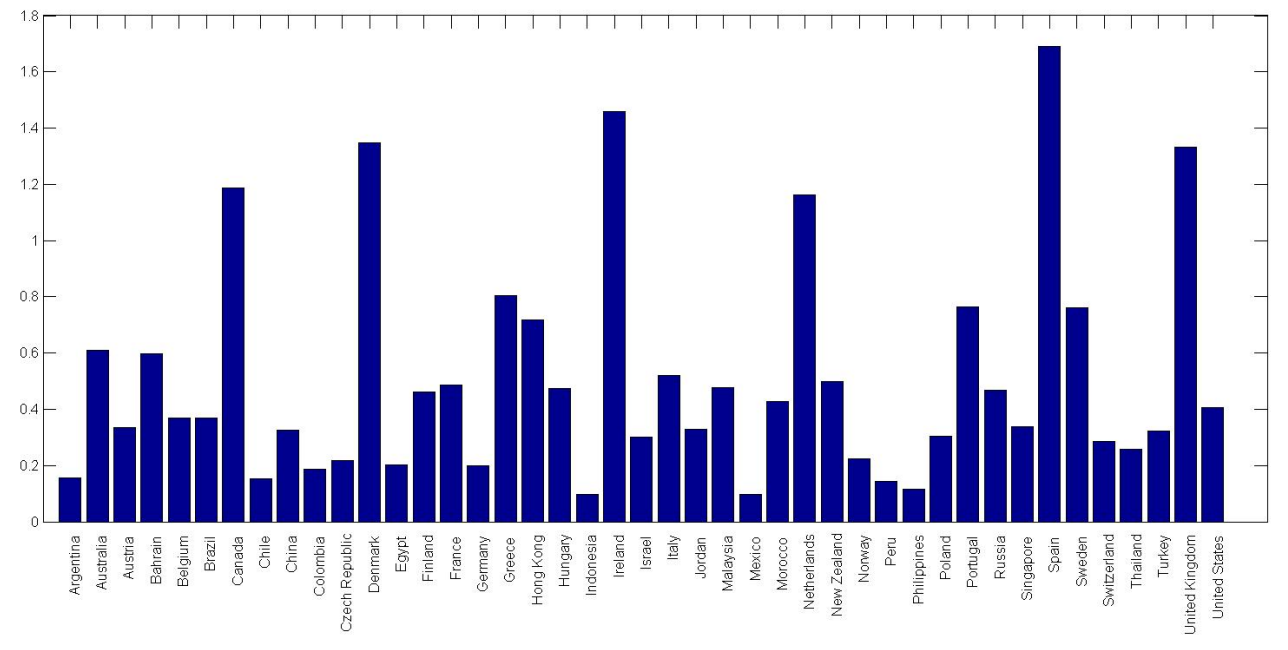

Figure 4: "Reality based" direct semi-elasticities for FININT 


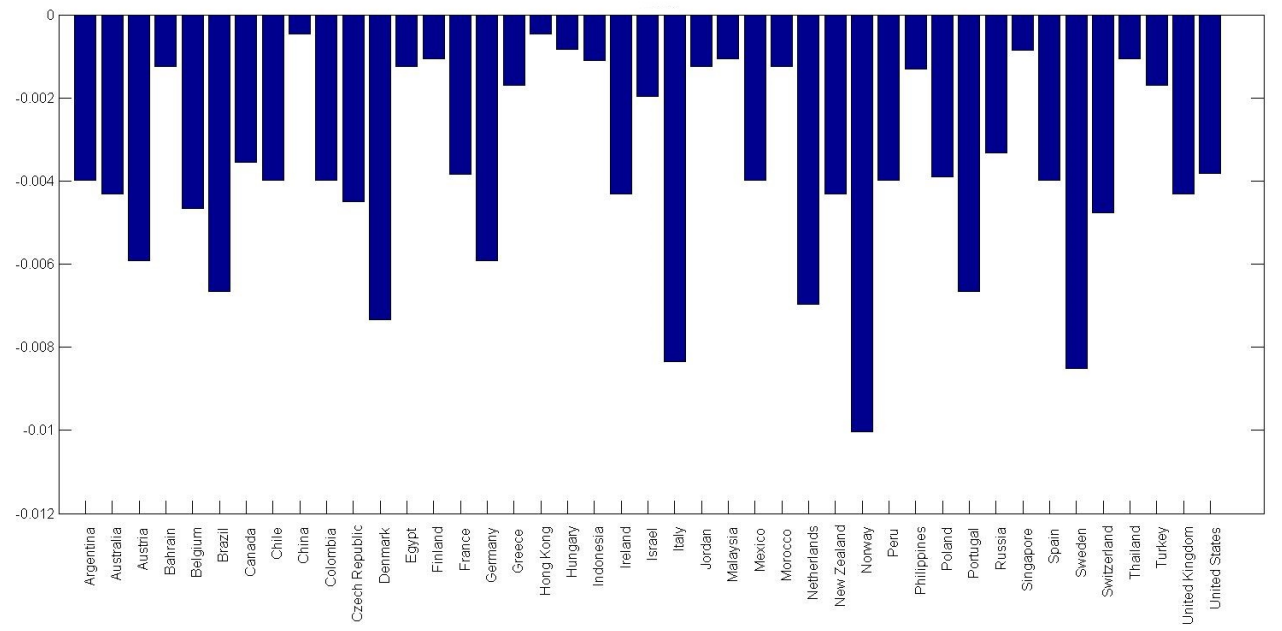

Figure 5: Standard indirect semi-elasticities for FININT

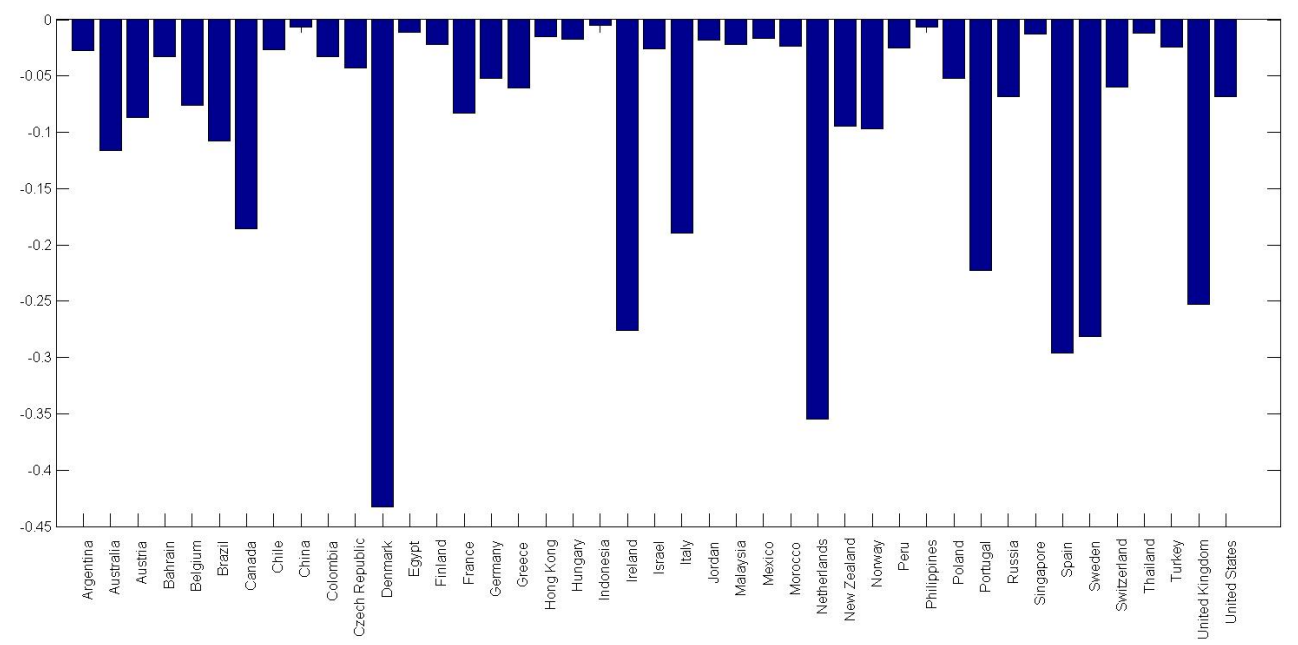

Figure 6: "Reality based" Indirect semi-elasticities for FININT 